\title{
An approach to constrain maximum horizontal stress magnitude using wellbore Failure observations from image logs
}

\author{
Do Quang Khanh
}

\begin{abstract}
The magnitude of the maximum horizontal stress is generally the most challenging term in estimating the full stress tensor. In this paper, an approach to constrain the magnitude of the maximum horizontal stress using the frictional limits to stress and wellbore failure observations (drillinginduced tensile fractures DITFs and/or breakouts BOs) from image logs is presented. This approach is applied to constrain the magnitude of the maximum horizontal stress at some interest depths $(3900 \mathrm{~m}$, $4100 \mathrm{~m}, 4300 \mathrm{~m}$ and $4500 \mathrm{~m}$ ) of the basement reservoirs at the White Tiger field, Cuu Long basin, Vietnam from the program STRESS POLYGON. The occurrence of DITFs and/or BOs proved to be useful in estimating stresses around the wellbore, especially the maximum horizontal stress magnitude.
\end{abstract}

Index Terms-Maximum horizontal stress, frictional limits to stress, wellbore failures, drillinginduced tensile fractures, breakouts.

\section{INTRODUCTION}

$\mathrm{K}$ nowledge of in-situ stress is an important issue for understanding of many processes in both science and engineering problems such as geology, geophysics, earthquake, civil, mining and petroleum development. It is also a key parameter for the petroleum exploration and production activities such as drilling borehole stability, hydraulic fracture stimulation, reservoir drainage and flooding patterns, subsurface fluid transport, storage and extraction of oil and gas from the subsurface $[1,6]$.

The state of in-situ stress is described by a stress tensor including the magnitudes and orientations

Manuscript Received on August 7th, 2017. Manuscript Revised December 25th, 2017

This research is funded by Ho Chi Minh City University of Technology - VNU-HCM, under grant number C2017-20-24.

Do Quang Khanh - Faculty of Geology and Petroleum Engineering, Ho Chi Minh City University of Technology VNU-HCM, (e-mail: dqkhanh@ @ hcmut.edu.vn). of three principal stresses. In common, one principal stress is assumed vertically in sedimentary basins and thus the stress tensor can only consist of the magnitudes of vertical, minimum and maximum horizontal stresses along with the orientation of maximum horizontal stress. Among these four components, the magnitude of the maximum horizontal stress is generally the most challenging term in estimating the full stress tensor. It also plays an important role for engineering decisions in particular wellbore stability and reservoir management $[2,3,7,11,12]$.

In this study, first we will introduce the state of stress and frictional faulting theory. Next, the stresses and wellbore failure (drilling-induced tensile fractures DITFs and/or breakouts BOs) analysis around a wellbore are presented. An approach to constrain the magnitude of the maximum horizontal stress using the frictional limits to stress and wellbore failure observations (drilling-induced tensile fractures DITFs and/or breakouts BOs) from image logs is presented. At the given interest depths, commonly values of the vertical stress $S_{v}$, the minmum horizontal stress $S_{\text {hmin }}$ and the pore pressure $P_{p}$ are known then the magnitude of the maximum horizontal stress $S_{H \max }$ can be constrained by the observations of the wellbore failures on logging images and the frictional faulting theory (frictional limits to stress). Finally, this approach is applied to constrain the magnitude of the maximum horizontal stress at some interest depths $(3900 \mathrm{~m}$, $4100 \mathrm{~m}, 4300 \mathrm{~m}$ and $4500 \mathrm{~m}$ ) of the basement reservoirs at the White Tiger field, Cuu Long basin, Vietnam. The occurrence of DITFs and/or BOs proved to be useful in estimating stresses around the wellbore, especially the maximum horizontal stress magnitude. 


\section{STATES OF IN-SITU STRESS AND FRICTIONAL LIMITS TO STRESS}

\section{$2.1 \quad$ States of in-situ stress}

According to the relative magnitudes of the vertical stress and two mutually perpendicular horizontal stresses, principal stresses $\left(S_{1} \geq S_{2} \geq S_{3}\right)$ are assumed vertical and horizontal stresses are and classified three possible states of stress and associated faulting styles which consist of normal faulting (NF), strike-slip faulting (SF) and reverse faulting (RF) as shown in Figure 1.

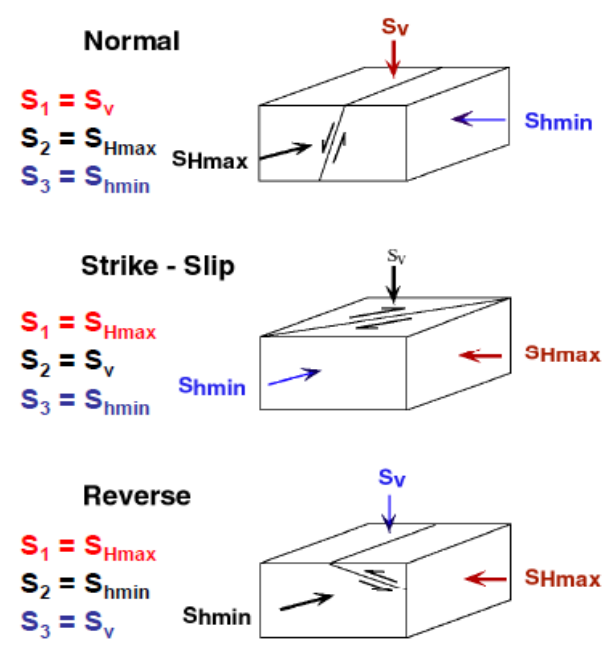

Figure 1. The three states of stress and associated types of faulting [5]

The different states of stress and associated fault styles are the normal faulting (NF) stress regime $\left(S_{\mathrm{v}} \geq S_{\mathrm{H} \text { max }} \geq S_{\mathrm{hmin}}\right)$, the strike-slip faulting (SF)

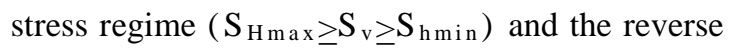
faulting (RF) stress regime $\left(S_{\mathrm{Hmax}} \geq S_{\mathrm{hmin}} \geq S_{\mathrm{v}}\right)$. These three states of stress correspond to the three commonly seen modes of faulting in the earth's crust and are used to describe relative stress magnitudes in the earth's crust.

\subsection{Frictional Limits to Stress}

The stresses at which rocks in the subsurface fail provide useful theoretical limits to the magnitudes of in-situ stresses. The ratio of the maximum to minimum effective stress that causes slip on pre-existing faults that are optimally oriented with respect to the stress field was determined by:

$$
\frac{S_{1}-P_{p}}{S_{3}-P_{p}}=f(\mu)=\left[\mu+\left(\mu^{2}+1\right)^{1 / 2}\right]^{2}
$$

If the ratio exceeds the above function of $\mu$ (usually from 0.6 to 1.0 ), then slip occurs in order to reduce that ratio to within frictional limits. This ratio can be used to constrain the ratio of the magnitudes of the maximum and minimum stress in seismically active regions. Furthermore, it can be used to place upper or lower bounds on the maximum and minimum stress magnitude respectively in seismically inactive regions. Depending on the stress regime of in-situ stress, the above equation becomes:

$$
\begin{aligned}
& \frac{S_{v}-P_{p}}{S_{h \min }-P_{p}}=\left[\mu+\left(\mu^{2}+1\right)^{1 / 2}\right]^{2}, \text { for } \mathrm{NF} \\
& \frac{S_{H \max }-P_{p}}{S_{h \min }-P_{p}}=\left[\mu+\left(\mu^{2}+1\right)^{1 / 2}\right]^{2}, \text { for } \mathrm{SF} \\
& \frac{S_{H \max }-P_{p}}{S_{v}-P_{p}}=\left[\mu+\left(\mu^{2}+1\right)^{1 / 2}\right]^{2}, \text { for } \mathrm{RF}
\end{aligned}
$$

The allowable values for the horizontal principal stresses in the Earth's crust are calculated by the above equations.

\section{STRESSES AROUND A WELLBORE AND WELLBORE FAILURE ANALYSIS}

\subsection{Stresses around a wellbore}

Assuming the vertical stress is a principal stress and the rock behaves elastically, stresses around a vertical cylindrical wellbore are considered in cylindrical coordinates. A set of equations describing the stress components around a circular borehole subjected to far in-situ stresses in a thick, homogenous, isotropic elastic medium is developed. The three principal wellbore stresses of a vertical cylindrical wellbore of radius $\mathrm{R}$ are the effective radial stress $\left(\sigma_{\mathrm{rr}}\right)$, the effective axial stress $\left(\sigma_{\mathrm{zz}}\right)$ and the effective circumferential stress $\left(\sigma_{\theta \theta}\right)$.

Mathematically, the effective stresses around a vertical cylindrical wellbore of radius $R$ are described in terms of a cylindrical coordinate system by the following equations [11]:

$$
\begin{gathered}
\sigma_{\theta \theta}=\frac{1}{2}\left(S_{H \max }+S_{H \min }-2 P_{p}\right)\left(1+\frac{R^{2}}{r^{2}}\right)- \\
\frac{1}{2}\left(S_{H \max }-S_{H \min }\right)\left(1+3 \frac{R^{4}}{r^{4}}\right) \cos 2 \theta-\Delta P \frac{R^{2}}{r^{2}} \\
\sigma_{r r}=\frac{1}{2}\left(S_{H \max }+S_{H \min }-2 P_{p}\right)\left(1-\frac{R^{2}}{r^{2}}\right)+ \\
\frac{1}{2}\left(S_{H \max }-S_{H \min }\right)\left(1-4 \frac{R^{2}}{r^{2}}+3 \frac{R^{4}}{r^{4}}\right) \cos 2 \theta+ \\
\Delta P \frac{R^{2}}{r^{2}} \\
\tau_{r \theta}=\frac{1}{2}\left(S_{H \max }-S_{H \min }\right)\left(1+2 \frac{R^{2}}{r^{2}}-3 \frac{R^{4}}{r^{4}}\right) \sin 2 \theta
\end{gathered}
$$

where $R_{r e}$ is the tangential shear stress, $R$ is the radius of the hole, $r$ is the radial distance from the 
center of the well, $\theta$ is measured from the azimuth of $\mathrm{S}_{\mathrm{H} \max }$, and $\Delta \mathrm{P}$ is the difference between the mud (or wellbore fluid) pressure $\mathrm{P}_{\mathrm{m}}$ in the wellbore and the pore pressure $\mathrm{P}_{\mathrm{p}}$ in the surrounding formation.

At the wellbore wall where $R=r$, these stress components reduce to:

$$
\begin{aligned}
\sigma_{\theta \theta}= & \left(S_{H \max }+S_{H \min }-2 P_{p}\right)- \\
& 2\left(\mathrm{~S}_{\mathrm{H} \text { max }}-\mathrm{S}_{\mathrm{H} \min }\right) \cos 2 \theta-\Delta \mathrm{P} \\
\sigma_{\mathrm{rr}}= & \Delta \mathrm{P} \\
\tau_{\mathrm{re}}= & 0
\end{aligned}
$$

The axial stress at the wellbore wall can be calculated using:

$$
\sigma_{\mathrm{zz}}=\mathrm{S}_{\mathrm{v}}-\mathrm{P}_{\mathrm{p}}-2 \mathrm{v}\left(\mathrm{S}_{\mathrm{Hmax}}-\mathrm{S}_{\mathrm{H} \min }\right) \cos 2 \theta
$$

where $\mathrm{v}$ is Poisson's ratio.

The above equations are rewritten in terms of the far-field principal stresses as follows:

$$
\begin{aligned}
\sigma_{\theta \theta}= & \left(S_{H \max }+S_{H \min }\right)- \\
& 2\left(S_{H \max }-S_{H \min }\right) \cos 2 \theta-P_{\mathrm{w}}-P_{\mathrm{p}} \\
\sigma_{\mathrm{rr}}= & \mathrm{P}_{\mathrm{w}}-\mathrm{P}_{\mathrm{p}} \\
\sigma_{\mathrm{zz}}= & \mathrm{S}_{\mathrm{v}}-2 \mathrm{v}\left(\mathrm{S}_{\mathrm{H} \max }-\mathrm{S}_{\mathrm{H} \min }\right) \cos 2 \theta-\mathrm{P}_{\mathrm{p}}
\end{aligned}
$$

where $\mathrm{P}_{\mathrm{w}}$ is the wellbore fluid (mud) pressure.

\subsection{Wellbore failure analysis}

Drilling-induced tensile fractures (DITFs)

Drilling induced tensile fractures (DITFs) are stress-induced tensile fractures of the wellbore wall. Tensile failure occurs when the wellbore stress concentration is less than the tensile strength of the rock.

The circumferential stress is minimized at $\theta=0^{0}$, so we have:

$$
\sigma_{\text {eөmin }}=3 \mathrm{~S}_{\mathrm{hmin}}-\mathrm{S}_{\mathrm{H} \max }-\mathrm{P}_{\mathrm{w}}-\mathrm{P}_{\mathrm{p}}
$$

Drilling-induced tensile fractures DITFs form when:

$$
\sigma_{\text {eөmin }}=3 \mathrm{~S}_{\mathrm{hmin}}-\mathrm{S}_{\mathrm{Hmax}}-\mathrm{P}_{\mathrm{w}}-\mathrm{P}_{\mathrm{p}}<\mathrm{T}
$$

where $T$ is the rock tensile strength and $T<0$.

The tensile rock strength is typically small compared to the compressive rock strength and rocks typically contain planes of weakness on which the tensile rock strength is negligible. Consequently, tensile rock strength can be assumed to be negligible [3]. Hence, DITFs tend to occur when $\sigma_{\ominus \ominus \min }$ is less than zero.

\section{Breakouts (BOs)}

Borehole breakouts (BOs) are stress-induced ovalizations of the cross-sectional shape of the wellbore. This occurs when the wellbore stress concentration exceeds that required to cause compressive failure of intact rock.

Assuming that the rock surrounding the wellbore is subjected to three principal stresses. If these stresses exceed the rock strength, the rock will fail. The stress state at the wellbore wall at the azimuth of $S_{\text {hmin }}$ (where the stress concentration is most compressive) is compared to a failure law defining the strength of the rock.

The circumferential stress is maximized at $\theta=$ $\pm 90^{\circ}$, so we have:

$$
\begin{aligned}
& \sigma_{\ominus e \max }=3 \mathrm{~S}_{\mathrm{Hmax}}-\mathrm{S}_{\mathrm{hmin}}-\mathrm{P}_{\mathrm{w}}-\mathrm{P}_{\mathrm{p}} \\
& \text { Breakouts BOs form when: } \\
& \sigma_{\text {eөmax }}=3 \mathrm{~S}_{\mathrm{H} \max }-\mathrm{S}_{\mathrm{hmin}}-\mathrm{P}_{\mathrm{w}}-\mathrm{P}_{\mathrm{p}}>\mathrm{C}
\end{aligned}
$$

The appropriate rock strength $\mathrm{C}$ considered in breakout calculations is typically the uniaxial compressive rock strength (UCS).

\section{AN APPROACH TO CONSTRAIN THE MAXIMUM HORIZONTAL STRESS MAGNITUDE USING THE FRICTIONAL LIMITS THEORY AND WELLBORE FAILURE OBSERVATIONS}

The magnitude of the maximum horizontal stress is generally the most challenging term in estimating the full stress tensor. The presence or absence of wellbore failures (drilling-induced tensile fractures DITFs and/or breakouts BOs) from image logs may give the way to estimate more strictly and precisely this term at the interest depths. Constraining the maximum horizontal stress magnitude is based on the frictional limits theory and the constraints on the occurrence of wellbore failures $[12,10,7]$. Assuming the vertical stress is one of three principal stresses, the methodology of this approach may describe in following basic steps.

First, apply the frictional limits theory with the assumed coefficient of frictional sliding on preexisting plane of weakness to establish the polygon stress at any given depth as well as the known values of the vertical stress $S_{v}$ and the pore pressure $\mathrm{P}_{\mathrm{p}}$ for different state of stress. The polygon stress will give the range of allowable values of horizontal stresses at any given depth. The outer periphery of the polygon stress corresponds to the critical stress state resulting in faulting. The stress polygon established from the frictional faulting theory at any given depth with an assumed coefficient of friction $\mu$ (usually as 0.6) also a good tool to constrain values of the minimum horizontal stress $S_{\mathrm{hmin}}$ and the maximum horizontal stress $S_{H \max }$. Depend on the stress regimes we have the different constraints on the maximum horizontal stress magnitude as following:

For the regime of normal faulting (NF): 


$$
\left[\mathrm{S}_{\mathrm{v}}+(\mathrm{f}(\mu)-1.0) * \mathrm{P}_{\mathrm{p}}\right] / \mathrm{f}(\mu) \leq \mathrm{S}_{\mathrm{Hmax}} \leq \mathrm{S}_{\mathrm{v}},
$$

For the regime of strike-slip faulting (SF):

$$
\mathrm{S}_{\mathrm{v}} \leq \mathrm{S}_{\mathrm{Hmax}} \leq \mathrm{S}_{\mathrm{hmin}} * \mathrm{f}(\mu)-(\mathrm{f}(\mu)-1.0) * \mathrm{P}_{\mathrm{p}} \text {, }
$$

For the regime of reverse faulting $(R F)$ :

$$
\mathrm{S}_{\mathrm{v}} \leq \mathrm{S}_{\mathrm{Hmax}} \leq \mathrm{f}(\mu) * \mathrm{~S}_{\mathrm{v}}-(\mathrm{f}(\mu)-1.0) * \mathrm{P}_{\mathrm{p}},
$$$$
\text { where } f(\mu)=\left[\left(1+\mu^{2}\right)^{0.5}+\mu\right]^{2}
$$

Second, use wellbore failure observations from image logs to establish more strictly and precisely constraints on the range of allowable values of horizontal stresses at any given depth when the presence or absence of induced wellbore failures (drilling-induced tensile fractures DITFs and/or breakouts BOs) with respect to the rock strength.

DITFs occur if the wellbore stresses are less than the tensile rock strength. So, a lower bound to $\mathrm{S}_{\mathrm{Hmax}}$ can be determined where DITFs are observed (usually assuming the tensile rock strength to be negligible at the petroleum basins) as:

$$
\mathrm{S}_{\mathrm{Hmax}} \geq 3 \mathrm{~S}_{\mathrm{hmin}}-\mathrm{P}_{\mathrm{p}}-\mathrm{P}_{\mathrm{w}}
$$

BOs occur if the wellbore stresses are exceeded the compressive rock strength $\mathrm{C}$. The compressive strength can be measured from samples or predicted prior at the petroleum basins (usually the uniaxial compressive strength UCS). So, a lower bound to $\mathrm{S}_{\mathrm{Hmax}}$ can be also determined as:

$$
\mathrm{S}_{\mathrm{H} \max } \geq\left(\mathrm{S}_{\mathrm{hmin}}+\mathrm{P}_{\mathrm{p}}+\mathrm{P}_{\mathrm{w}}+\mathrm{C}\right) / 3
$$

In general the wellbore is in balance (i.e. $\mathrm{P}_{\mathrm{w}}=$ $\mathrm{P}_{\mathrm{p}}$ ), the constraints on the occurrence of wellbore failures will be:

$$
\mathrm{S}_{\mathrm{H} \max } \geq 3 \mathrm{~S}_{\mathrm{hmin}}-2 \mathrm{P}_{\mathrm{p}} \text {, for DITFs }
$$

$\mathrm{S}_{\mathrm{H} \max } \geq\left(\mathrm{S}_{\mathrm{hmin}}+2 \mathrm{P}_{\mathrm{p}}+\mathrm{C}\right) / 3$, for BOs

Finally, by gaining information on the minimum horizontal stress magnitude determined leak-off tests or hydraulic fracturing tests, along with the stress polygon and induced constraints on wellbore failure observations the magnitude of the maximum horizontal stress $\mathrm{S}_{\mathrm{H} \max }$ will be constrained more strictly and precisely. At the known value of the minimum horizontal stress, the frictional limits of the stress polygon usually give an upper-bound of the maximum horizontal stress magnitude. The lines corresponding to the occurrence of induced failures may provide us a lower-bound of the maximum horizontal stress magnitude.

These constraints from the occurrence of BOs and/or DITFs and the faulting limit theory are the basic for the establishment of the stress polygon and constraints by the program STRESS POLYGON written by the Matlab language.

\section{CONSTRAINING THE MAXIMUM HORIZONTAL STRESS MAGNITUDE AT THE WHITE TIGER FIELD, VIETNAM}

\subsection{Geological background}

The White Tiger (Bach Ho) field, a fractured granitic basement reservoir is located in the center of Cuu Long basin, offshore Southern Vietnam (Figure 2). It is an unusual buried hill reservoir with the fractured reservoir matrix largely made up of unaltered acid igneous lithologies (mostly granites and granodiorites) [4].

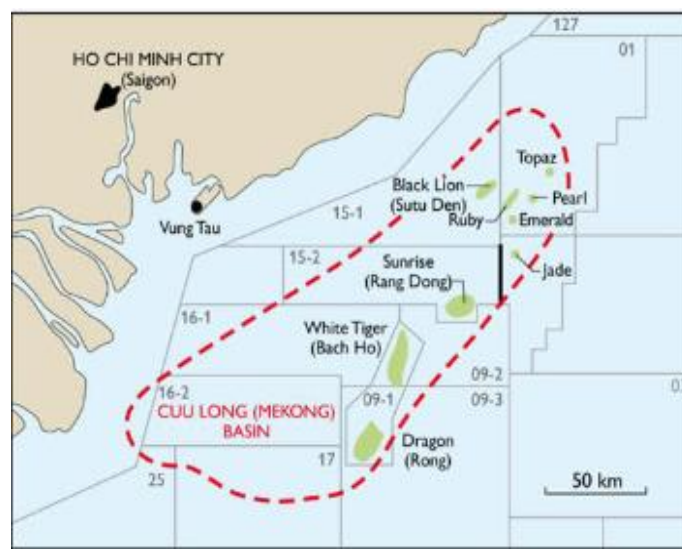

Figure 2. Location map of the White Tiger field, Cuu Long basin

The shallowest part of the highly fractured buried hill at the White Tiger field lies at a depth of $3050 \mathrm{~m}$ (Figure 3), while the effective base for liquids production in this field is typical shallower than $4650 \mathrm{~m}$. However, the deepest producing interval in the field is a fractured zone at $5013 \mathrm{~m}$. The productive intervals in the White Tiger wells are invariably fractured zones in the basement formation usually at $3500-4500 \mathrm{~m}$. 


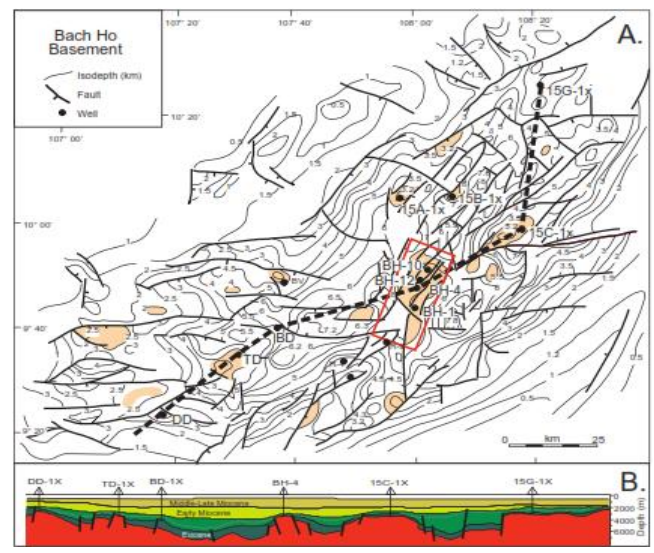

Figure 3. Basement distribution at the White Tiger field, Cuu Long basin [9]

\section{The vertical stress}

Based on data acquired of wellbores together with the integration density technique, the vertical stress (overburden stress) at the White Tiger field is closely approximated by the power law $\mathrm{S}_{\mathrm{v}}=0.0093^{*} \mathrm{Z}^{1.1066}$, where $\mathrm{S}_{\mathrm{v}}$ is in $\mathrm{MPa}$ and $\mathrm{Z}$ is depth in meters (Figure 4).

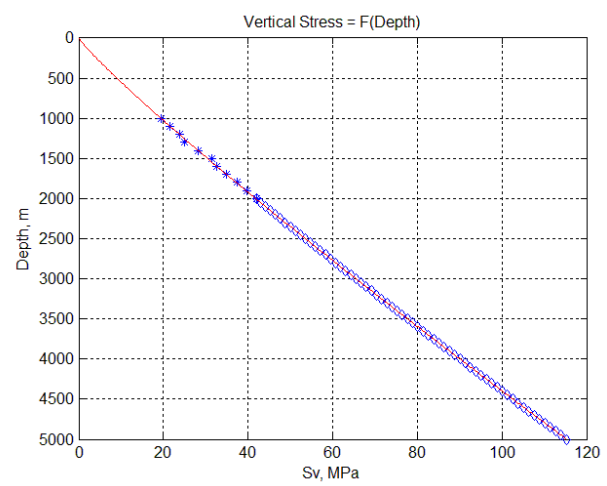

Figure 4. Vertical stress or overburden stress at the White Tiger field.

\section{The pore pressure}

Pore pressures are determined from 20 DST measurements and 12 WFIT measurements at wellbores in the White Tiger. Although an overpressure occurs in the interval of the Oligocene formation, the pore pressure gradient is lightly higher than the normal hydrostatic pressure gradient as $10.35 \mathrm{MPa} / \mathrm{km}$ [0.45 psi/ft] (Figure 5).

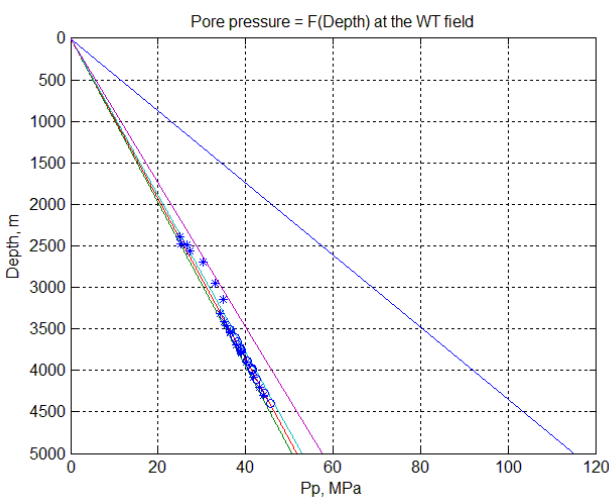

Figure 5. Pore pressure at the White Tiger field

The magnitude of minimum horizontal stress

Based on the treating pressure data of hydraulic fracturing tests at 04 wellbores, we interpret these closure pressures The magnitudes of minimum horizontal stresses at the fracturing depths will be equal to the closure pressures.

Although 04 hydraulic fracturing tests carried out at Oligocene formation, from these data the gradient of the minimum horizontal stress can be closely approximated to $0.63 \mathrm{psi} / \mathrm{ft} \quad[14.49$ $\mathrm{MPa} / \mathrm{km}$ ] (Figure 6). So, the values of minimum horizontal stress are higher than the normal hydrostatic pressures with their gradient $\sim 0.44$ $\mathrm{psi} / \mathrm{ft}$ [10.0 MPa/km], but lower than the lithostatic pressures with their gradient $\sim 1.0 \mathrm{psi} / \mathrm{ft}[23.0$ $\mathrm{MPa} / \mathrm{km}]$.

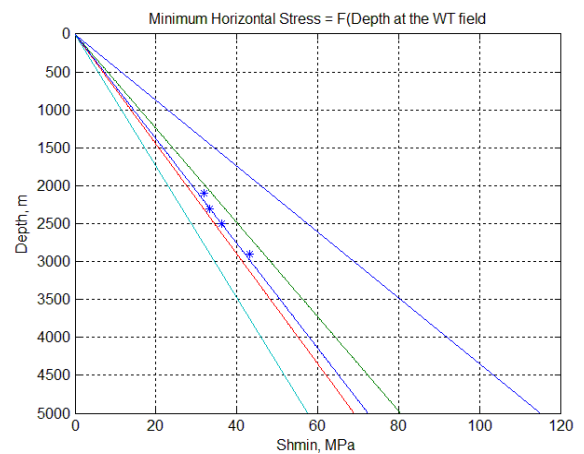

Figure 6. Minumum horizontal stress at the White Tiger field

Data on wellbore failure observations from image logs

Data on wellbore failures inferred from highresolution image logs (CAST-V and FMI images). A lot of image logs were run in the basement reservoirs at the White Tiger field in which the wellbore breakouts and/or drilling-induced tensile fractures were observed (Figure 7). 


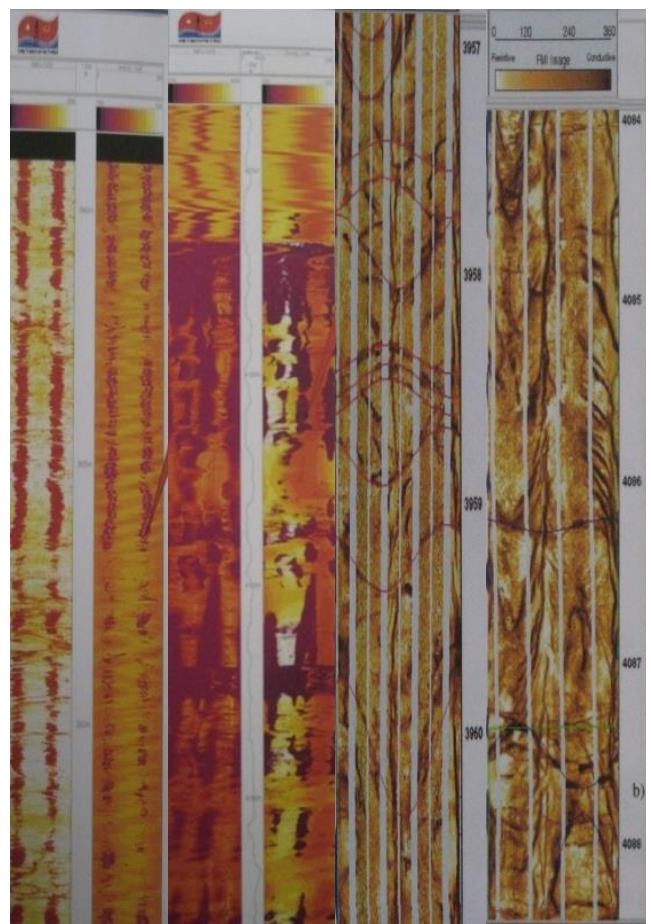

Figure 7. Examples of the occurence of BOs and DITFs of the wellbores at the White Tiger field

In the basement reservoirs at the White Tiger, four interest depths of $3900 \mathrm{~m}, 4100 \mathrm{~m}, 4300 \mathrm{~m}$ and $4500 \mathrm{~m}$ are considered. At the depths of $3900 \mathrm{~m}$ and $4100 \mathrm{~m}$, only the wellbore breakouts occur but no drilling induced tensile fractures. However, at the depths of $4300 \mathrm{~m}$ and $4500 \mathrm{~m}$ no breakouts but a lot of drilling-induced tensile fractures occur.

Therefore, after that we will use these wellbore failures to constrain the valuable magnitudes of the maximum horizontal stress at these interest depths in the basement reservoirs at the White Tiger field combining with the stress polygon of the frictional limits assuming the common coefficient of friction $\mu=0.6$.

\subsection{Constraining the magnitude of the maximum horizontal stress}

The magnitude estimation of the maximum horizontal stress is the most difficult aspect of the in-situ stress tensor to constrain in the White Tiger field. The maximum horizontal stress magnitude can be determined from the observation of wellbore failures (BOs and/or DITFs) or from the hydraulic fracturing tests or constrained using the frictional limits to stress.

No fracture reopening pressure can be determined where minifracture tests are conducted in cased holes. Therefore, no estimate of the magnitude of the maximum horizontal stress $S_{H \max }$ can be made from minifracture tests at the White Tiger field. However, a lot of image logs were run in basement reservoirs at the White Tiger field in which BOs and/or DITFs were observed. So we will use these wellbore failure observations from image $\operatorname{logs}$ to estimate the maximum horizontal stress magnitudes in basement reservoirs at the White Tiger field combining with the stress polygon of the frictional limits assuming the common coefficient of friction $\mu=0.6$.

At a given interest depths of the basement reservoirs at the White Tiger field, commonly values of the vertical stress $S_{v}$, the minimum horizontal stress $S_{h m i n}$ and the pore pressure $P_{p}$ are known then the valuable magnitude of the maximum horizontal stress $S_{\mathrm{Hmax}}$ can be constrained by the observations of the wellbore failures on image logs.

In the basement reservoirs at the White Tiger, we will consider at four interest depths $(3900 \mathrm{~m}$, $4100 \mathrm{~m}, 4300 \mathrm{~m}$ and $4500 \mathrm{~m}$ ). At the depths of $3900 \mathrm{~m}$ and $4100 \mathrm{~m}$, no drilling-induced tensile fractures DITFs but a lot of breakouts BOs are observed. However, at the depths of $4300 \mathrm{~m}$ and $4500 \mathrm{~m}$ no breakouts but a lot of drilling-induced tensile fractures are observed.

From the known data at these four interest depths, we use the program STRESS POLYGON to establish the stress polygon and constraints of the occurrence of BOs and/or DITFs at these depths as shown in Figure 8. From these diagrams, we could constrain the magnitude of the maximum horizontal stress more strictly and precisely.

At depth of $3900 \mathrm{~m}$ there are a lot of BOs but no DITFs from image logs

Known values of the vertical stress $S_{\mathrm{v}}(87.57$ $\mathrm{MPa})$, the pore pressure $\mathrm{P}_{\mathrm{p}}(40.37 \mathrm{MPa})$ at this depth are used to establish the stress polygon of the frictional limits to stress assuming the coefficient of friction $\mu=0.6$. With the tensile rock strength assumed negligible and the UCS assumed as $110 \mathrm{MPa}$, the constraint lines on the occurrence of BOs and DITFs are also established. From the known value of the minimum horizontal stress $\mathrm{S}_{\mathrm{hmin}}(56.61 \mathrm{MPa})$ at this depth, the upper bound of the stress polygon, the lower bound of the occurrence of DITFs and the lower bound of the occurrence of BOs will be respectively $90.72 \mathrm{MPa}$, 88.79 MPa and 82.42 MPa (Figure 8a).

Because there are a lot of BOs but no DITFs at this depth, the magnitude of maximum horizontal stress $\mathrm{S}_{\mathrm{Hmax}}$ may be higher than $82.42 \mathrm{MPa}$ (lower bound of the occurrence of BOs with the UCS 
assumed as $110 \mathrm{MPa}$ ) but lower than $88.79 \mathrm{MPa}$ (lower bound of the occurrence of DITFs). In this case the upper bound of the stress polygon (90.72 $\mathrm{MPa}$ ) is higher than the lower bound of the occurrence of DITFs $(88.79 \mathrm{MPa})$, therefore the valuable magnitude of maximum horizontal stress $\mathrm{S}_{\mathrm{Hmax}}$ may range from $82.42 \mathrm{MPa}$ to $88.79 \mathrm{MPa}$.

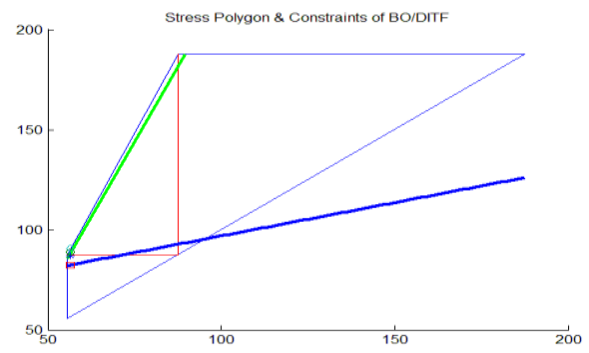

a) Diagram at the depth of $3900 \mathrm{~m}$.

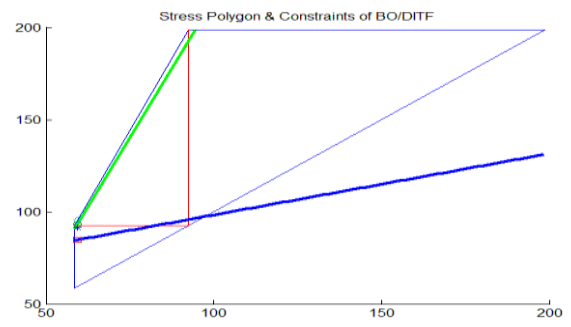

b) Diagram at the depth of $4100 \mathrm{~m}$.

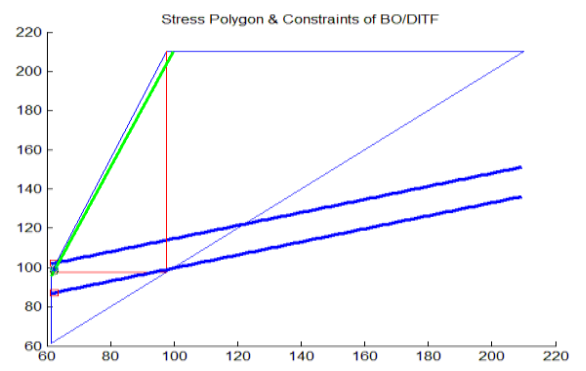

c) Diagram at the depth of $4300 \mathrm{~m}$.

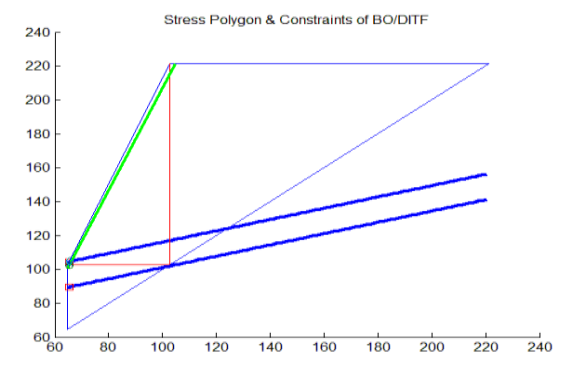

d) Diagram at the depth of $4500 \mathrm{~m}$.

Figure 8. Diagrams of the stress polygon and constraints on DIFTs and/or BOs

At depth of $4100 \mathrm{~m}$ there are also a lot of BOs but no DITFs from image logs
Known values of the vertical stress $\mathrm{S}_{\mathrm{v}}(92.55$ $\mathrm{MPa})$, the pore pressure $\mathrm{P}_{\mathrm{p}}(42.44 \mathrm{MPa})$ at this depth are used to establish the stress polygon of the frictional limits to stress assuming the common coefficient of friction $\mu=0.6$. With the tensile rock strength assumed negligible and the UCS assumed as $110 \mathrm{MPa}$, the constraint lines on the occurrence of BOs and DITFs are also established. From the known value of the minimum horizontal stress $S_{\text {hmin }}(59.41 \mathrm{MPa})$ at this depth, the upper bound of the stress polygon, the lower bound of the occurrence of DITFs and the lower bound of the occurrence of BOs will be respectively $95.38 \mathrm{MPa}$, 93.35 MPa and 84.76 MPa (Figure 8b).

Similarly to the case at the depth of $3900 \mathrm{~m}$, because there are a lot of BOs but no DITFs at this depth the magnitude of maximum horizontal stress $\mathrm{S}_{\text {Hmax }}$ may be higher than $84.76 \mathrm{MPa}$ (lower bound of the occurrence of BOs with the UCS assumed as $110 \mathrm{MPa}$ ) but lower than 93.35 MPa (lower bound of the occurrence of DITFs). In this case the upper bound of the stress polygon $(95.38 \mathrm{MPa})$ is also higher than the lower bound of the occurrence of DITFs (93.35 MPa), therefore the valuable magnitude of maximum horizontal stress $\mathrm{S}_{\mathrm{Hmax}}$ may also range from 84.76 $\mathrm{MPa}$ to $93.35 \mathrm{MPa}$.

At depth of $4300 \mathrm{~m}$ there are a lot of DITFs but no BOs from image logs

Known values of the vertical stress $S_{v}$ (97.56 $\mathrm{MPa})$, the pore pressure $\mathrm{P}_{\mathrm{p}}(44.51 \mathrm{MPa})$ at this depth are used to establish the stress polygon of the frictional limits to stress assuming the common coefficient of friction $\mu=0.6$. With the tensile rock strength assumed negligible and the UCS assumed as $155 \mathrm{MPa}$, the constraint lines on the occurrence of BOs and DITFs are also established. From the known value of the minimum horizontal stress $\mathrm{S}_{\mathrm{hmin}}(62.31 \mathrm{MPa})$ at this depth, the upper bound of the stress polygon, the lower bound of the occurrence of DITFs and the lower bound of the occurrence of BOs will be respectively 100.04 $\mathrm{MPa}, 97.91 \mathrm{MPa}$ and $102.11 \mathrm{MPa}$ (Figure 8c).

Because there are a lot of DITFs but no BOs at this depth the magnitude of maximum horizontal stress $\mathrm{S}_{\mathrm{Hmax}}$ may be higher than 97.91 MPa (lower bound of the occurrence of DITFs) but lower than 102.11 MPa (lower bound of the occurrence of BOs with the UCS assumed as $155 \mathrm{MPa}$ ). In this case the upper bound of the stress polygon (100.04 $\mathrm{MPa}$ ) is lower than the lower bound of the occurrence of BOs (102.11 MPa), therefore the valuable magnitude of maximum horizontal stress $\mathrm{S}_{\mathrm{Hmax}}$ may range more strictly and precisely from 97.91 MPa to 100.04 MPa.At this depth, basement rocks may be stronger than because if the UCS 
assumed as $110 \mathrm{MPa}$ then BOs will occur. Moreover, the stress regime at this depth may change from normal faulting to strike-slip faulting.

At depth of $4500 m$ there are also a lot of DITFs but no BOs from image logs

Known values of the vertical stress $S_{\mathrm{v}}(102.60$ $\mathrm{MPa})$, the pore pressure $\mathrm{P}_{\mathrm{p}}(46.58 \mathrm{MPa})$ at this depth are used to establish the stress polygon of the frictional limits to stress assuming the common coefficient of friction $\mu=0.6$. With the tensile rock strength assumed negligible and the UCS assumed as $155 \mathrm{MPa}$, the constraint lines on the occurrence of BOs and DITFs are also established. From the known value of the minimum horizontal stress $\mathrm{S}_{\mathrm{hmin}}(65.21 \mathrm{MPa})$ at this depth, the upper bound of the stress polygon, the lower bound of the occurrence of DITFs and the lower bound of the occurrence of BOs will be respectively 104.70 $\mathrm{MPa}, 102.47 \mathrm{MPa}$ and 104.46 MPa (Figure 8d).

Similarly to the case at the depth of $4100 \mathrm{~m}$, because there are a lot of DITFs but no BOs at this depth the magnitude of maximum horizontal stress $\mathrm{S}_{\mathrm{Hmax}}$ may be higher than 102.47 MPa (lower bound of the occurrence of DITFs) but lower than 104.46 $\mathrm{MPa}$ (lower bound of the occurrence of BOs with the UCS assumed as $155 \mathrm{MPa}$ ). However, in this case the upper bound of the stress polygon (104.70 MPa) is higher than the lower bound of the occurrence of BOs (104.46 MPa), therefore the valuable magnitude of maximum horizontal stress $S_{\text {Hmax }}$ may range from 102.47 $\mathrm{MPa}$ to $104.46 \mathrm{MPa}$.

\section{CONCLUSIONS}

An integrating approach to constrain the maximum horizontal stress magnitude is established from theory of the frictional limits to stress and constraints on the occurrence of wellbore failures (DITFs and/or BOs) from image $\log$.

The stress polygon established from frictional limits to stress with an assumed coefficient of friction $\mu$ will give the range of allowable values of horizontal stresses at any given depth when values of the vertical stress, the pore pressure are known. Especially, it is useful to check the known value of the minimum horizontal stress before constrain the magnitude of the maximum horizontal stress. The constraints established from the occurrence of wellbore failures (DITFs and/or BOs) will constrain the maximum horizontal stress magnitude more strictly and precisely. The presence or absence of DITFs s and/or BOs from image logs proved to be useful in estimating stresses around the wellbore, especially the maximum horizontal stress magnitude.

\section{REFERENCES}

[1] B. Amadei, and O. Stephansson, "Rock stress and its measurement," Chapman \& Hall, 1997, pp. 23-94.

[2] C. A. Barton, D. Moos, P. Peska, and M. D. Zoback, "Utilizing wellbore image data to determine the complete stress tensor: Application to permeability anisotropy and wellbore stability", The log analyst, pp. 21-33, 1997.

[3] M. Brudy, M. and D. Zoback, "Drilling-induced tensile wall- fractures: Implications for determination of in-situ stress orientations and magnitudes," Int. J. of Rock Mech. and Min. Sci., vol. 36, pp. 191-215, 1999. Moos and Zoback, 1990.

[4] T. X. Cuong and J. K. Warren, "Bach Ho field, a fractured granitic basement reservoir, Cuu Long basin, offshore SE Vietnam: A "buried-hill" play", J. of Petroleum Geology, vol. 32(2), pp.129-156, 2009.

[5] T. Engelder, "Stress regimes in the lithosphere," Princeton, N.J., Princeton University Press, 1993, pp. 4557.

[6] E. Fjaer, R. M. Holt, P. Horsrud, A. M. Raaen, and R. Risnes, "Petroleum related rock mechanics", Developments in Pet. Sci. 53, $2^{\text {nd }}$ Elsevier B.V, 2008, pp. 19-49.

[7] D. Q. Khanh, "Characterizing the full in-situ stress tensor and its applications for petroleum activities," Ph.D. dissertation, Dept. of Energy and Resourses Engineering, Chonnam National University, Korea, 2013.

[8] D. Moos, and M. D. Zoback, "Utilisation of observations of wellbore failure to constrain the orientation and magnitude of crustal stresses: Application to continental, Deep Sea Drilling Project, and Ocean Drilling Program boreholes," J. of Geophysical Research, vol. 95, pp. 9305-9325, 1990.

[9] P. H. Que, "History of geological development of the Cuu Long Basin," PetroVietnam Review, vol. 2, pp. 5-16, 1994.

[10] R. Sanaee, S. R. Shadizadeh, and M. A. Riahi, "Determination of the stress profile in a deep borehole in a naturally fractured reservoir," Int. J. Rock Mec. \& Min. Sci, vol. 47-4, pp. 599-605, 2010.

[11] M. D. Zoback, "Reservoir geomechanics," Cambridge University Press, New York, 2010, pp. 1-449.

[12] M. D. Zoback, C. A. Barton, M. Brudy, D. A. Castillo, T. Finkbeiner, B. R. Grollimund, D. B. Moos, P. Peska, C.D. Ward, and D. J. Wiprut, "Determination of stress orientation and magnitude in deep wells," Int. J. Rock Mec. \& Min. Sci., vol. 40, pp. 1049-1076, 2003.

Do Quang Khanh received the B.E. (1986), M.E degree in Mechanics from Ho Chi Minh City University of Technology (HCMUT) (1993), M.Sc. degree in European Construction Mechanics from University of Liège (Ulg), Belgique (1997) and Ph.D. degree in Engineering on Energy and Resources Engineering from Chonnam National University (CNU), Korea (2013).

Now, he is Head of Division on Modelling and Simulation in Petroleum and Geology 
Engineering, Faculty of Geology \& Petroleum Engineering, Ho Chi Minh City University of Technology (HCMUT), Vietnam National University - Ho Chi Minh City (VNU-HCM), Vietnam. He was also a lecturer and Former Head of Dept. of Drilling - Production and Petroleum Technology, Faculty of Geology and Petroleum Engineering, Ho Chi Minh City University of Technology (HCMUT), Vietnam National University - Ho Chi Minh City (VNU-HCM), Vietnam.
His main research interests are Mechanics, Modelling \& Simulation Issues in Geology and Petroleum Engineering, Energy and Resources Engineering such as Rock Mechanics, Geomechanis, Technologies and Equipment on Oil \& Gas Drilling - Production, Enhanced Oil Recovery, Well Completion and Reservoir Stimulation, New and Renewable Energy Resources.

\title{
Một phương pháp ràng buộc độ lớn ứng suất ngang lớn nhất dùng các quan sát hư hỏng giếng khoan
}

\author{
Đỗ Quang Khánh
}

Tóm tắt-Độ lớn ứng suất ngang lớn nhất thường là thành phần thách thức nhất trong việc xác định tensor ứng suất. Trong bài báo này, phương pháp ràng buộc độ lớn ứng suất ngang lớn nhất dùng các giới hạn ma sát với ứng suất và các quan sát hư hỏng giếng khoan (các khe nứt kéo sinh ra trong khoan DITFs và/hay các sạt lở BOs) từ các $\log$ hình ảnh được trình bày. Phương pháp này được áp dụng để ràng buộc độ lớn ứng suất ngang lớn nhất tại các độ sâu quan tâm $(3900 \mathrm{~m}, 4100 \mathrm{~m}, 4300 \mathrm{~m}$ và $4500 \mathrm{~m})$ của các vỉa tầng móng ở mỏ Bạch Hổ, bồn trũng Cửu Long, Việt nam từ chương trình STRESS POLYGON. Sự xuất hiện của DITFs và/hay BOs đã chứng tỏ là rất hữu ích trong việc ước tính các ứng suất quanh giếng khoan, đặc biệt độ lớn ứng suất ngang lớn nhất.

Tù khóa-Ứng suất ngang lớn nhất, giới hạn ma sát với ứng suất, hư hỏng giếng, khe nứt kéo sinh ra trong khoan DITFs, sạt lở BOs. 